\title{
PANCRÁCIO NO RIO DAS COBRAS: \\ O USO DE LITERATURA NO ENSINO DE HISTÓRIA
}

Francisco Oliveira ${ }^{1}$

Ronyere Ferreira ${ }^{2}$

Vilmar Aires dos Santos ${ }^{3}$

\section{INTRODUÇÃO}

Ao empreender esta reflexão partimos do entendimento de que os cursos de licenciatura carecem de outras abordagens metodológicas e, no caso da História, uma das possíveis maneiras se faz com a socialização de fontes que são utilizadas pelos historiadores, como por exemplo, a literatura.

Neste diálogo, tomamos a liberdade de pedir desculpas a Nelson Rodrigues, pois teremos que refutá-lo: nem toda unanimidade é burra, há sempre as exceções que birram com as regras e no tocante ao ensino na Educação Básica brasileira, felizmente, podemos nos deparar com várias exceções.

Parece ser unânime na sociedade a concepção de que a educação, principalmente a da esfera pública, está muito aquém do que a coletividade aspira, não formando indivíduos críticos e muito menos permitindo o desenvolvimento intelectual dos estudantes. Mesmo os que algum proveito tiram de tal situação, quando se deparam com olhos atentos e ansiosos por declarações, fazem da voz do povo as suas e comungam com o discurso da ineficiência.

Tomando por base tal pensamento e a dinâmica do contexto educacional brasileiro verifica-se a necessidade de reformulações curriculares em todas as áreas da Educação Básica, porém, estas exigências ganham ares escatológicos em alguns campos do conhecimento, dentre eles, a História, que a despeito de mudanças sugeridas principalmente pelos Parâmetros Curriculares Nacionais PCN, com o decorrer dos anos vem amargando desprestígio e ocupando cada vez menos espaço nos currículos escolares.

\footnotetext{
${ }^{1}$ Mestre em História e Professor da Rede Estadual do Piauí. E-mail: Ihs_francisco@hotmail.com.

${ }^{2}$ Mestre em História e Professor da Rede Estadual do Piauí. E-mail: rony-001@hotmail.com.

${ }^{3}$ Professora Adjunta IV, do Departamento de Métodos e Técnicas de Ensino(DMTE/CCE/UFPI). Coordenadora da Residência Pedagógica em Históri/CMPP. Doutoranda em Educação (USP). Email: vilmaraires@yahoo;com.br
} 
Dentre os motivos para a perda de espaço da disciplina História no currículo escolar podemos apontar o pouco interesse que a área tem provocado nos estudantes, assim como a pequena visibilidade sobre a necessidade de se ter conhecimentos do passado, isso justifica a busca incessante por novas metodologias e novas abordagens. Por isso, aqui defendemos o pressuposto de que uma das melhores formas de se desenvolver o gosto por essa matéria escolar pode ser através da socialização e uso de fontes históricas não convencionais, como é o caso da literatura.

O uso de ferramentas tradicionalmente trabalhadas por historiadores e pelos professores da Educação Básica consiste em um procedimento metodológico que faz deste profissional um pesquisador (BOTELHO, 2012), o que, na contemporaneidade, é considerado como algo ideal, pois não há ensino sem pesquisa, assim como pesquisa sem ensino (FREIRE, 1996).

"Pancrácio no Rio das Cobras" é o produto da reflexão feita para o uso em sala de aula da crônica "Bons Dias" que foi escrita por Machado de Assis, com alunos do $9^{\circ}$ ano do Centro de Ensino de Tempo Integral Darcy Araújo, escola do Ensino Fundamental da rede estadual de ensino do Piauí, no tocante aos debates sobre os últimos anos da escravidão no Brasil, na forma de projeto de intervenção didática proposto pelo Programa Institucional de Bolsa de Iniciação à Docência PIBID/História-UFPI.

Tal título justifica-se como uma alusão à crítica "machadiana" sobre o mundo letrado, contida no final da crônica utilizada, em que, equivocadamente, para a sociedade, a prova de que os negros foram realmente libertos seria sua inclusão no "veneno" das letras, nas faculdades tão valorizadas em fins do século XIX e início do século $X X$.

Portanto, aqui abordaremos o uso da literatura na sala de aula, que, entendemos, contribui para que os estudantes deixem de "associar o domínio do conhecimento de História à capacidade de memorização, em detrimento da análise e interpretação que deveriam instrumentalizar reflexões críticas sobre a existência humana de outras épocas e lugares." (BOTELHO, 2012, p.2). 
O presente artigo ${ }^{4}$ foi organizado nas seguintes partes: $O$ ensino de História hoje, que busca através do diálogo com alguns autores caracterizar o ensino da disciplina. Em seguida realiza-se uma articulação entre ensino, História e literatura, numa segunda parte, o texto apresenta a crônica "Bons Dias" de Machado de Assis, descrevendo o uso da mesma no projeto realizado. Como notas conclusivas, destacamos a possibilidade de uso exitoso da literatura nas aulas de História.

\section{O ENSINO DE HISTÓRIA HOJE}

Segundo Bittencourt (2011), o ensino da História desde o século XIX tem permanecido nos currículos escolares dos diferentes níveis do ensino básico e também como matéria dos cursos preparatórios ou exames de vestibulares brasileiros. Para a autora, a História, enquanto disciplina possui uma longa historicidade, permeada de conflitos e controvérsias na elaboração de seus conteúdos e métodos.

O ensino da disciplina vem sendo alvo de pesquisadores que buscam compreender sua historiografia, todas as evoluções e suas errâncias ao longo do caminho. O que podemos observar é que o seu ensino foi alvo de intenso debate, lutas políticas e teóricas no contexto de resistências à política educacional da ditadura civil-militar brasileira, ocorrida de 1964 a1984.

Portanto, a reflexão sobre esse ensino na década de 1980 marcou decisiva renovação que ocorreu principalmente nas práticas pedagógicas no âmbito da educação básica e quiçá na educação superior. Afinal de contas, ao ingressarmos na licenciatura em história uma das primeiras indagações é o questionamento que ao mesmo tempo parece uma provocação aos acadêmicos: afinal, para que serve a história?

Com auxílio da experiência propiciada pelo PIBID História, perguntamo-nos como ensinar História hoje? Com tal indagação notamos que devemos analisar o ensino contemporâneo pela ótica da multidisciplinaridade, ou seja, um ensino que não é formado por ilhas de conhecimento, exigindo uma frequente relação entre as

\footnotetext{
${ }^{4}$ Este artigo possui sua versão original publicada na obra FRANÇA-CARVALHO, A. D.; MARTINS, C. H. R.; CONDE, E. P.; MONTEIRO, H. R. de S. (org.) Estratégias de ensino: propostas multidisciplinares de aprendizagens significativas. Teresina, EDUFPI, 2013.
} 
áreas do conhecimento, o que contribui significativamente para uma melhor compreensão por parte dos estudantes.

O lugar ocupado pelo ensino de História, tanto na LDB como nos PCN, evidencia uma disciplina que tem sido alvo de intensas pesquisas e publicações acadêmicas, como destaca Silva; Fonseca (2010, p. 13):

\begin{abstract}
Nessa perspectiva, o lugar ocupado pela História, após 14 anos da implantação (LDB - Lei de Diretrizes e Bases da Educação - Lei 9.394/96) e 13 anos da divulgação dos Parâmetros Curriculares Nacionais pelo Ministério da Educação, está, intimamente, imbricado às intencionalidades educativas expressas na política educacional implementada na década de 1990 , no contexto político de globalização da economia, de desenvolvimento de novas tecnologias e de consolidação da democracia no Brasil. Esse lugar deriva de mudanças na política educacional e no ensino de História, conquistadas no processo de lutas na década de 1980 e, também, a partir da promulgação da Constituição Federal de 1988.
\end{abstract}

Alguns autores destacam que a ênfase dos PCN no ensino e na aprendizagem de temas e problemas da História do Brasil, desde os anos iniciais do ensino fundamental, não tem sido suficientes para o enfrentamento de velhos problemas em muitas realidades do ensino. Dentre eles, o fato de os estudantes, ao concluírem essa primeira fase escolar, terem pouco contato direto com a História do Brasil.

Apesar dessa ênfase dos PCN, não podemos afirmar que os desafios acabaram, nem que o ensino de História está no ápice e que deve ser indiferente a mudanças, contudo, percebemos que o papel do professor-educador se reveste de grande capacidade de despertar nos alunos o senso crítico de análise, que pode ocorrer com a quebra da exclusividade do livro didático enquanto recurso metodológico.

Como destaca Fonseca (1990), o livro didático é um dos instrumentos mais estudados no ensino de História. A preocupação com o conteúdo dos manuais de História é antiga. A ênfase é principalmente no seu conteúdo, capacidade de criticidade, e também no tocante a perpetuação de tal objeto pedagógico como fonte única para os estudantes, retirando assim, do conhecimento histórico sua dimensão discursiva entre correntes interpretativas divergentes e/ou concordantes.

\title{
3 ENSINO, HISTÓRIA E LITERATURA
}


O uso da linguagem literária no ensino de História nem de longe se apresenta como uma novidade metodológica, porém, afirmar que os professores de tal área envolvem-se no uso deste artifício com destreza pode ser enganoso, todavia, não é de hoje que a relação existente entre as duas disciplinas é pensada. Desde a década de 80, autores apresentam disposição em analisar criticamente essa afinidade entre História e Literatura, ramos do conhecimento que aparentemente são distintos.

Para Santos:

(...) história e literatura são vistas de formas diferentes como áreas do conhecimento. A história é objetiva. A literatura subjetiva. A história tem por objeto de estudo o passado. A obra literária é reconhecida como tal quando antecipa o devir, o futuro. A história tem por pressuposto a verdade. A literatura é ficcional. (...) A história tem um discurso oficial. Na literatura o discurso é polifônico. (2001, p.02).

Sobre a relação entre História e Literatura Queiroz, destaca:

A história trata essencialmente do real, é um testemunho da sociedade, refere-se a uma trama complexa e efetiva de acontecimentos. A literatura, para o que nos interessa, considera os possíveis da História, os possíveis até mesmo irrealizáveis, alude essencialmente ao virtual. (2006, p.81).

No entanto, apesar de pertencerem a campos de saberes distintos, História e Literatura, em sua essência, englobam o tratamento da vida humana, este que é interesse permanente tanto para o historiador quanto para o literato. (QUEIROZ, 2006).

Foi a partir da década de 90 que os historiadores demonstraram uma maior aceitação da literatura como fonte histórica e também no ensino de outras disciplinas. Contudo, defende-se que esta não seja aceita como verdade, mas que possa ser questionada e analisada como qualquer outro manancial histórico, (SANTOS, 2008), considerando-se o espaço de criação, as articulações pessoais cotidianas dos literatos, assim como o contexto social mais amplo.

A possibilidade de utilizar a literatura em sala de aula para contribuir com uma análise mais fundamentada e menos simplista dos processos históricos devese principalmente a uma ampliação da noção de fontes e quebra de paradigmas, 
com a validade destas não sendo mais questionadas, como ocorrido no passado (OGAWA; NEVES, 2011).

Essa ampliação de fontes e abordagens deveu-se a uma noção renovada da História, nas últimas décadas, que aborda essencialmente o cotidiano, o social, o imaginário, conteúdos que antes não eram considerados, isso principalmente a partir da experiência da historiografia francesa. (QUEIROZ, 2006).

O uso da literatura como documento histórico permite que os estudantes tenham contato com o ofício do historiador e suas ferramentas, ou seja, as fontes, contribuindo assim para a desmistificação da disciplina e uma revisão da imagem do professor e do livro didático como detentores de toda verdade, além de aguçar a curiosidade dos estudantes sobre o passado. Desta forma, Botelho assim se posiciona:

Ao perceber como o historiador constrói um conhecimento a partir da análise de fontes, altera-se por completo a percepção do estudante do ensino básico sobre o significado da História. Fica evidenciado de forma concreta como é possível conjecturar, elaborar hipóteses e interpretar um documento, por exemplo, com o objetivo de compreender aspectos (...) que muitas vezes não são explicitados no livro didático. (2012, p. 03).

Assim, “(...) aguça-se a curiosidade dos alunos e evita-se que caiam no senso comum, torna-se uma bisbilhotice crítica, deixando seu estágio de ingenuidade" (FREIRE, 1996, p.32). Esta, que é propiciada pela abordagem histórica positivista predominante nos manuais didáticos, em muitos casos escondem as contradições, omitem a dialética social. Assim, permitem a perpetuação do pensamento deturpado de História que chega ao público estudantil, que tende a aceitá-la como verdade única, pronta e inacabada. A mudança desta visão depende, em grande parte, das concepções do professor, que ao optar pela interdisciplinaridade como diálogo entre História e Literatura, permite que o estudante construa uma visão de mundo mais completa e menos simplista. (SANTOS, 2011).

Desta forma, quando se realiza juntamente com os estudantes a análise de um texto literário, Ihes apresentando uma História possível de identificação, feita por pessoas comuns e não feita por heróis e "semideuses", possibilitamos a visão de que a sociedade brasileira de fins do Império, assim como qualquer outra, era heterogênea, é contraditória e, portanto, humana. 


\title{
4 "BONS DIAS", UMA ANÁLISE HISTÓRICA
}

\author{
Utilizamos em sala de aula a crônica "Bons Dias" de Machado de Assis, que \\ foi publicada pelo jornal Gazeta de Notícias em 19 de Maio de 1888, no Rio de \\ Janeiro, poucos dias após a Lei Áurea. Para fazermos uma análise deste documento \\ optamos aqui pela reprodução integral, apesar da possibilidade de ser cansativo:
}

\section{BONS DIAS}

Eu pertenço a uma família de profetas après coup, post factum, depois do gato morto, ou como melhor nome tenha em holandês. Por isso digo, e juro se necessário for, que toda a história desta Lei de 13 de Maio estava por mim prevista, tanto que na segunda-feira, antes mesmo dos debates, tratei de alforriar um molecote que tinha, pessoa de seus dezoito anos, mais ou menos. Alforriá-lo era nada; entendi que, perdido por mil, perdido por mil e quinhentos, e dei um jantar.

Neste jantar, a que meus amigos deram o nome de banquete, em falta de outro melhor, reuni umas cinco pessoas, conquanto as notícias dissessem trinta e três (anos de Cristo), no intuito de lhe dar um aspecto simbólico.

No golpe do meio (coup du milieu, mas eu prefiro falar a minha língua), levantei-me eu com a taça de champanha e declarei que acompanhando as idéias pregadas por Cristo, há dezoito séculos, restituía a liberdade ao meu escravo Pancrácio; que entendia a que a nação inteira devia acompanhar as mesmas idéias e imitar o meu exemplo; finalmente, que a liberdade era um dom de Deus, que os homens não podiam roubar sem pecado.

Pancrácio, que estava à espreita, entrou na sala, como um furacão, e veio abraçar-me os pés. Um dos meus amigos (creio que é ainda meu sobrinho) pegou de outra taça, e pediu à ilustre assembléia que correspondesse ao ato que acabava de publicar, brindando ao primeiro dos cariocas. Ouvi cabisbaixo; fiz outro discurso agradecendo, e entreguei a carta ao molecote. Todos os lenços comovidos apanharam as lágrimas de admiração. Caí na cadeira e não vi mais nada. De noite, recebi muitos cartões. Creio que estão pintando o meu retrato, e suponho que a óleo.

No dia seguinte, chamei o Pancrácio e disse-lhe com rara franqueza:

-Tu és livre, podes ir para onde quiseres. Aqui tens casa amiga, já conhecida e tens mais um ordenado, um ordenado que...

-Oh! meu senhô! Fico.

-... Um ordenado pequeno, mas que há de crescer. Tudo cresce neste mundo; tu cresceste imensamente. Quando nasceste, eras um pirralho deste tamanho; hoje estás mais alto que eu. Deixa ver; olha, és mais alto quatro dedos...

-Artura não qué dizê nada, não, senhô...

-Pequeno ordenado, repito, uns seis mil-réis; mas é de grão em grão que a galinha enche o seu papo. Tu vales muito mais que uma galinha.

-Eu vaio um galo, sim, senhor.

-Justamente. Pois seis mil-réis. No fim de um ano, se andares bem, conta com oito. Oito ou sete.

Pancrácio aceitou tudo; aceitou até um peteleco que the dei no dia seguinte, por me não escovar bem as botas; efeitos da liberdade. Mas eu expliquei-lhe que o peteleco, sendo um impulso natural, não podia anular 0 direito civil adquirido por um título que Ihe dei. Ele continuava livre, eu de mau humor; eram dois estados naturais, quase divinos. Tudo compreendeu o meu bom Pancrácio; daí para cá, tenho-lhe despedido alguns pontapés, um 
ou outro puxão de orelhas, e chamo-lhe besta quando lhe não chamo filho do Diabo; coisas todas que ele recebe humildemente, e (Deus me perdoe!) creio que até alegre.

O meu plano está feito; quero ser deputado, e, na circular que mandarei aos meus eleitores, direi que, antes, muito antes de abolição legal, já eu, em casa, na modéstia da família, libertava um escravo, ato que comoveu a toda a gente que dele teve notícia; que esse escravo tendo aprendido a ler, escrever e contar, (simples suposição) é então professor de filosofia no Rio das Cobras; que os homens puros, grandes e verdadeiramente políticos, não são os que obedecem à lei, mas os que se antecipam a ela, dizendo ao escravo: és livre, antes que o digam os poderes públicos, sempre retardatários, trôpegos e incapazes de restaurar a justiça na terra, para satisfação do Céu.

BOAS NOITES (ASSIS, 1888)

O texto caracteriza-se como uma ironia acerca dos últimos anos de escravidão no Brasil, trazendo em seu bojo um imenso leque de interpretações e possibilidades sobre o cotidiano das décadas finais do Império e das relações escravistas brasileiras. Passemos então a algumas delas: Machado de Assis, abertamente, opta pela comicidade, exagerando no simbolismo bíblico e na submissão do bom escravo denominado de Pancrácio. Aparentemente, o autor enfatiza a continuação das relações de exploração e ironiza a atitude dos abolicionistas de última hora, "aqueles que, ao apagar das luzes, insistiam em anunciar alforrias festivamente pelos jornais" (SHALHOUB, 1990, p.100).

No entanto, Shalhoub (1990), ressalta que o autor da crônica aponta implicitamente e talvez principalmente a falência das relações trabalhistas e o uso de alforrias como forma de produção de dependentes, como na passagem em que o narrador diz ter Pancrácio crescido e constata que o negro o supera em altura em quatro dedos. Mas o crescimento não se fez fisicamente:

\footnotetext{
O moleque - assim como os escravos em geral- havia crescido "imensamente" nos últimos dezoito anos; isto é, os negros haviam assumido atitudes mais firmes no sentido de obter a liberdade nesse período. Essa interpretação é enfatizada pela idade de Pancrácio... (1990, p.101).
}

Portanto, se o escravo descrito tinha mais ou menos os seus 18 anos, ele nascera pouco tempo depois da chamada lei do Ventre Livre, momento que podemos considerar como decisivo e de crise do sistema escravista brasileiro, o que parece ser constatado por Machado de Assis. 
Outra interpretação referente à crônica é a de que se alguém estava no momento histórico de direcionar pontapés e ofensas era o bom Pancrácio, pois o narrador "entende tanto o sentido dos acontecimentos quanto a sua total impossibilidade de mudar as coisas, sendo que suas ações são apenas tentativas de salvar as aparências" (CHALHOUB, 1990, p.101). Assim como seu ex senhor, Pancrácio também tinha alguma consciência de momento vivenciado, sendo assim, sua submissão grotesca pode não passar de mais uma brincadeira de nosso cronista, pois o negro sabia e afirmava: "eu vaio um galo, sim, senhor."

Outro aspecto que pode ser abordado a partir da análise da crônica é a tensão existente na relação dos senhores escravocratas e o Estado, este que desde a transferência da corte do Império para o Brasil, ocorrida em 1808, interferira cada vez mais no cotidiano da sociedade da nova sede, provocando ressentimentos na ordem patriarcal que até então era vigente.

Durante todo 0 texto 0 narrador procura manter as aparências de dominação, de que era o senhor dirigente naquela situação, porém, ele se entrega e admite sua incapacidade: "Alforriá-lo era nada; entendi que, perdido por mil, perdido por mil e quinhentos, e dei um jantar.".

Claramente, podemos construir a imagem de um senhor de escravos que não suportava o pensamento de perder sua propriedade, devido uma determinação estatal. Melhor para seu orgulho seria "acompanhar as idéias de Cristo". O ressentimento fica mais evidente no momento em que o narrador exalta-se em detrimento ao Estado, que possui poderes "sempre retardatários, trôpegos e incapazes...".

Nosso cronista encerra dando uma alfinetada nos que aderiam à causa abolicionista no apagar das luzes, provocando-os com a afirmação de que por trás das notícias nos jornais estava a existência de interesses políticos.

Pelo que pudemos observar, Machado de Assis utilizou de forma destacável o seu ângulo privilegiado de visão social que era possibilitado pelo modelo de imprensa Periódica de fins do século XIX, (QUEIROZ 2008), padrão em que o Gazeta de Notícias, jornal pelo qual a crônica foi publicada, encaixa-se. Como cronista, produziu uma importante e rica fonte histórica, capturando em sua escrita o movimento social, o que pode ser utilizada pedagogicamente pelos profissionais da História no ensino básico no intuito de levar os estudantes a uma crítica análise do passado. 


\section{RUMO A SALA DE AULA}

O ensino de história na contemporaneidade é composto por uma série de desafios. Ao trabalharmos com o uso da literatura na sala de aula incorporamos uma multidisciplinaridade, fazendo com que a disciplina torne-se menos monótona e mais reflexiva. No entanto, para a utilização desse documento foi necessário uma reflexão sobre a relação existente entre História e Literatura, como a que fizemos anteriormente.

Utilizamos a crônica para propiciar uma análise possível sobre as últimas décadas de escravidão, para utilizá-la, preparamos e desenvolvemos juntamente com os estudantes do $9^{\circ}$ ano do ensino fundamental do Centro de Ensino de Tempo Integral Darcy Araújo, uma aula expositiva/dialogada a partir do capítulo do livro didático que aborda a mesma temática.

Após realizarmos uma leitura corrida e coletiva da crônica para um primeiro contato por parte dos estudantes, procedemos com outra, esta com pausas para comentários e uma análise mais aprofundada, focando principalmente nas interpretações feitas anteriormente.

Completando a intervenção didática, desenvolvemos uma atividade com os estudantes, composta por sete perguntas subjetivas e que foram divididas em duas categorias: dependentes e independentes. O primeiro conjunto eram questões em que exigiam que eles fizessem uma relação mais aprofundada entre o conteúdo contido no livro didático, a aula expositiva/dialogada e a análise da crônica que fizemos coletivamente; no segundo grupo de questões, a resposta exigia menos relação, sendo possível o "acerto" simplesmente com uma interpretação cuidadosa do texto escrito por Machado de Assis.

Ao corrigirmos as atividades, notamos que não havia um grande desequilíbrio no tocante aos acertos entre as duas categorias. No total, os estudantes acertaram $50 \%$ das questões independentes e $43,3 \%$ das dependentes, não demonstrando uma porcentagem satisfatória, mas que pode ser justificada pela inexperiência com esse tipo de metodologia.

Deixando a análise fria dos números, notamos que os estudantes demonstraram um maior interesse por se tratar de uma metodologia que não é recorrente e que foge da "mesmice" do livro didático, como destacou o estudante $\mathrm{J}$. L.: "Foi muito interessante, pois ter esse contato com o documento histórico nos 
proporcionou a experiência de conhecer de modo "profundo" (...) os fatos históricos". O comentário já leva a entender que ele pode compreender a História não como a verdade, mas como um olhar, uma interpretação.

Apesar dos dados quantitativos não possibilitarem grandes ânimos, podemos perceber que o projeto propiciou o início de uma modificação no olhar dos estudantes sobre a disciplina, levando-os a entenderem que a história não é uma sucessão de causas e efeitos e que é o produto de uma complexa relação de vários acontecimentos, como destacou a aluna P. C. ao ser questionada sobre os motivos da alforria do bom Pancrácio: "Por que ele queria ser deputado (...) e ele também não queria que o Estado interferisse na relação do dono do escravo com o escravo".

Na mesma indagação, a estudante A. B. nos respondeu com um tom irônico e utilizando o próprio texto para replicar: "Alforriá-lo era nada, entendi que, perdido por mil, perdido por mil e quinhentos e dei um jantar."

Apesar das análises feitas juntamente com os estudantes, talvez a pouca prática de analisar um documento, tenham influenciado pra que não ultrapassassem o sentido primário do texto, ou seja, a primeira impressão, como na resposta de J. C. sobre a relação de trabalho existente após a Lei Áurea: "Que ele libertou seu escravo e (...) continuou dando pontapés, petelecos...", levando-os a ignorar a possibilidade de ser uma ironia do autor, mas isso não se encaixa como erro e sim como escolha, pois as desconstruções dos sentidos mais claros só ocorrem com a apuração e ousadias intelectuais que somente a prática permite.

\section{CONSIDERAÇÕES FINAIS}

Através da análise da crônica acreditamos que os estudantes iniciaram uma reconstrução de suas noções sobre a escravidão e a História, levando-os a entender a disciplina como uma construção a partir das possibilidades e não exatamente como verdade imutável e cristalizada.

Em relação ao desenvolvimento do projeto, apesar de alguns desânimos que os números nos trouxeram, as respostas subjetivas demonstraram que os sujeitos interlocutores desta reflexão, os alunos, compreenderam minimamente que o passado, assim como o presente, se desenrola devido a anseios implícitos e explícitos, e que os fatos históricos não ocorrem por consequência de atos únicos, 
mas de uma complexa junção de fatores. Mostrando-nos assim, que o nosso objetivo: realizar uma análise reflexiva sobre o uso da literatura no ensino de História na Educação Básica foi atingido, pois se exercitou a criticidade e o debate entre os estudantes frente a uma fonte histórica não comumente utilizada na sala de aula.

A realização deste projeto mostrou-se importante também, na medida em que os alunos foram chamados a conhecer um texto que traz uma linguagem diferente da que estão acostumados com o livro didático, fazendo-os buscar significados para termos e palavras então desconhecidas.

Portanto, defendemos a literatura como uma possibilidade metodológica para o ensino de História. Seu uso deve ser planejado e orientado em conformidade com a realidade na qual se vai trabalhar, pois como qualquer outra fonte histórica pode ser usada no ensino básico, desde que, devidamente explicada como um texto escrito com outros fins que não o didático, mas que é dotado de capacidade de desenvolvimento do senso crítico e do potencial de levar ao entendimento do passado assim como ele é, complexo, dinâmico e em construção.

\section{REFERÊNCIAS}

BITTENCOURT, Circe Maria Fernandes. Ensino de história: fundamentos e métodos. 4. ed. São Paulo, 2011.

BOTELHO, Denílson. A primeira república na sala de aula: aprendendo história com processos criminais. Fênix - Revista de História e Estudos Culturais. Janeiro/ Fevereiro/ Março/ Abril de 2012 Vol. 9 Ano IX, no 1. Pág. 4. Disponível em: www.revistafenix.pro.br/PDF28/Artigo_5_Denilson_Botelho.pdf. Acesso em: 12 jun. 2013.

FONSECA, Selva Guimarães. Ensino de história: diversificação de abordagens/ livro: história em quadro negro. São Paulo: marco zero, 1990.

FREIRE, Paulo. Pedagogia da Autonomia: saberes necessárias à prática educativa. São Paulo: Paz e Terra, 1996.

FRANÇA-CARVALHO, A. D.; MARTINS, C. H. R.; CONDE, E. P.; MONTEIRO, H. R. de $S$. (org.) Estratégias de ensino: propostas multidisciplinares de aprendizagens significativas. Teresina, EDUFPI, 2013.

GAZETA DE NOTÍCIAS, 19 de Maio de 1888. Ano XIV, n 139. Rio de Janeiro. Pág.2.Disponível em: http://memoria.bn.br/DocReader/docreader.aspx?bib= 103730_02\&pasta=ano\%20188\&pesq. Acesso em: 12 jun. 2013. 
OGAWA, André Eitti. NEVES, Hudson Campos. Feições de uma experiência: literatura e poesia no ensino de história. In: SILVA, Cristiani Bereta. Experiências de ensino de história no estágio supervisionado. Florianópolis: Editora UDESC, 2011.

QUEIROZ, Teresinha de Jesus Mesquita. As diversões civilizadas em Teresina: 1880-1930. Teresina: FUNDAPI, 2008.

Teresinha de Jesus Mesquita. História e Literatura. In: Do singular ao plural. Recife: Edições Bagaço. 2006. p 81-94.

SANTOS, Ademar Firmino dos Santos. A literatura no ensino de História: 30 anos de pesquisa. In: SEPECH - Seminário de Pesquisa em Ciências Humanas. Londrina Eduel, v. 1, 2008.

SANTOS, Avacir Gomes dos. História e literatura: do prazer ao poder. In: Primeira Versão. Porto Velho: Nov. 2001. Disponível em: www.primeiraversao.unir.br/ atigos_pdf/numero061Avacir.pdf. Aceso em: 12 jun. 2013.

SHALHOUB, Sidney. Visões da liberdade: uma história das últimas décadas da escravidão na Corte - São Paulo: Companhia das Letras, 1990.

SILVA, Marcos Antonio da; FONSECA, Selma Guimarães. Ensino de História hoje: errâncias, conquistas e perdas. Revista Brasileira de História. São Paulo, v. 31, no 60, 2010. 